\title{
$\beta$-Galactosidase: Application in Dairy and Food Industry
}

\author{
Rakendhu Saji* and Smitha Balakrishnan \\ Department of Dairy Chemistry, SMC College of Dairy Science, Anand, Kamdhenu University, Gujarat, India \\ *Corresponding author: rakendhusaji1997@gmail.com
}

Received: $17-03-2021$

Revised: 28-05-2021

Accepted: 13-06-2021

\begin{abstract}
$\beta$-galactosidase is an enzyme which is highly important in dairy industry. The purpose of the enzyme is the hydrolysis of lactose. In addition to that it has other food applications. Due to the increasing incidence of lactose intolerance, this enzyme is gaining importance commercially. Many advancements have come with respect to this production of enzymes like biotechnological innovation and immobilization.
\end{abstract}

Keywords: $\beta$-galactosidase, Hydrolysis, Application, Lactose intolerance

The people with lactose digestion problem varies widely per country. $\beta$-galactosidase involves in the hydrolysis of lactose with an improvement in the solubility and digestibility of final products. Lactosefree dairy products can provide essential nutrients present in milk to people who are lactose intolerant. Because of the thermostability, thermo acidophilic and thermoresistant properties, microbial $\beta$-galactosidase is of much interest (Asraf and Gunasekaran, 2010). Different microorganisms are used to extract the enzyme $\beta$-galactosidase which is having industrial application.

Many advancements have come with respect to this production of enzymes like biotechnological innovation and immobilization and other applications are GOS production and dietary supplements (Dekker et al. 2019).

$\beta$-galactosidases can catalyse both hydrolytic and transglycosylation reactions. Properties of microbial beta-galactosidases such as transglycosylation and transgalactosylation have been utilized for production of glucose, galactose, heteropolysaccharide, galactooligosaccharides. Through Immobilization, $\beta$-galactosidase can improve its stability and reusage (Asraf and Gunasekaran, 2010).

Immobilization processes provide control of the matrix-enzyme interaction, allowing enzymes to be retained in a variety of orientations and conditions, which has remained a fundamental factor for their use in biotechnological sectors (Ansari et al. 2014).

The hydrolysis of lactose into glucose and galactose will improve the solubility and digestibility of milk and milk products thus, $\beta$-galactosidase is highly important in dairy industry. Food with low lactose content, ideal for lactose-intolerant consumers is thus obtained. It also favours consumers who are less tolerant to dairy products crystallization such as milk candy, condensed milk, frozen concentrated milk, yoghurt and ice-cream mixes. It also produces oligosaccharides, the best biodegradability of whey second to lactose hydrolysis (Saqib et al. 2017).

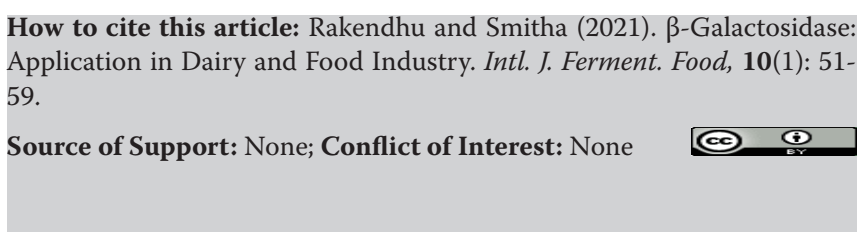




\section{$\beta$-galactosidase}

$\beta$-galactosidase (EC 3.1.2.23, $\beta$-D-galactoside galacto hydrolase) is often called by its trivial name lactase. It works in a relatively broad $\mathrm{pH}$ range enzymes from fungi act between $\mathrm{pH}$ 2.5-5.4, yeast and bacterial enzymes act between $\mathrm{pH}$ 6.0-7.0. $\beta$-galactosidases hydrolyse the disaccharide $\beta$-D-galactopyranosyl$(1,4)$-D-glucose (lactose) to $\beta$-D-galactose and D-glucose. The currently available commercial lactases differ widely in their properties, mainly with respect to their $\mathrm{pH}$ and temperature optima. Lactase which is present in the brush borders of the small intestine involves in the absorption of lactose. $\beta$-galactosidase enzyme produced by walls of small intestine and hydrolyse milk sugar lactose into glucose and galactose. Lack of lactase enzyme leads to lactose intolerance which shows symptoms such as abdominal pain, bloating, diarrhoea, gas and nausea (Ghatak et al. 2013; Bashir et al. 2020). Lack of the enzyme $\beta$-galactosidase leads to a higher concentration of indigested lactose in the large intestine. When the enzyme enters the large intestine, the osmotic balance is disturbed and absorbs more water and it is flushed out which is the cause of diarrhoea in lactose intolerant person (Husain, 2010). Glucose is an energy source, and galactose is essential for brain growth (Aggarwal et al. 2019).

\section{Lactose Intolerance}

Lactose intolerance is defined as a metabolic disorder when people are unable to digest significant amounts of lactose due to the genetically insufficient production of the lactase enzyme ( $\beta$-galactosidase) (Ibrahim and Gyawali, 2013).

Lactose intolerance is caused by a lack of $\beta$-galactosidase, which is not mediated by the immune system. Lactose is not digested into its component monosaccharides in the absence of this enzyme in the digestive tract, and instead travels into the colon, where bacteria metabolise the sugar. Lactose intolerance is caused by the products of this fermentation $\left(\mathrm{CO}_{2}, \mathrm{H}_{2}\right.$, and $\left.\mathrm{H}_{2} \mathrm{O}\right)$, which cause gastrointestinal irritation (Downs et al. 2013).
Lactase deficiency can be classified into three categories: primary, congenital, and secondary. People aged 2 to 20 years suffer from primary lactase insufficiency. A more prevalent type of lactase insufficiency is primary lactase deficit, which occurs when $\beta$-galactosidase production is diminished along the brush boundaries of the small intestine (lactase). The second form of lactase deficiency is congenital lactase deficiency, which is caused by a genetic defect that results in either a very tiny amount of this enzyme in patients or the enzyme being completely absent in affected persons. The third form, known as secondary lactase deficiency, is caused by low amounts of this enzyme as a result of an underlying GI tract illness (El-Gindy 2003). Lactose intolerance is common in Asian populations, with about $90 \%$ of people suffering from it. Lactose intolerance patients consume dairy-fermented items that have no or very little lactose (Saqib et al. 2017).

\section{Microbial $\beta$-galactosidase}

Because of its numerous roles, which include digestion, lysosomal degradation, and catabolism, $\beta$-galactosidase is widely distributed in nature (Mahoney, 2002). The main sources are (1) microorganisms mainly bacteria, fungi and yeast; (2) plants which include almonds, peaches, apricots, apples etc., and(3) animal organs (intestine, brain, skin). Major industrial sources of enzyme are Aspergillus sp. and Kluyveromyces sp. A variety of bacteria produce $\beta$-galactosidase. $\beta$-galactosidase is also produced by thermophilic lactic acid bacteria (LAB). At high temperatures, $\beta$-galactosidase of these cultures has a high level of stability and activity. The following are some of the reasons why these microorganisms are employed in scientific studies: (a) Lactose maldigesters exhibit no unpleasant or confrontational reactions to fermented milk products. (b) Because these microorganisms are Generally Regarded as Safe (GRAS), the $\beta$-galactosidase enzyme generated from them can be used without undergoing substantial purification. (c) Choosing the suitable strain for manufacture to boost lactose absorption (Nivetha and Mohanasrinivasan, 2017). 
Although a wide range of bacteria can generate $\beta$-galactosidase, Streptococcus thermophilus and Bacillus stearothermophilus are considered potential bacterial sources (Panesar et al. 2010). Lactose fermenting yeasts make intracellular $\beta$-galactosidase, which is a good supply of this enzyme. This enzyme has been utilised to make lactose-free milk products due to its high hydrolytic activity. Yeast lactases are most active in $\mathrm{pH}$ 6.0-7.0 buffers. Kluyveromyces marxianus has the ability to produce homologous enzymes like $\beta$-galactosidase, as well as heterologous proteins, and can thrive on a variety of substrates, including lactose as the sole carbon and energy source (Genari et al. 2003). Since, fungal $\beta$-galactosidases have an acidic pH-optima in the range of 2.5-5.4, they are most suited to hydrolyzing lactose found in acidic products like whey. Although fungal $\beta$-galactosidases are thermostable enzymes, they are more susceptible to product inhibition, which is primarily caused by galactose. Kluyveromyces lactis, Kluyveromyces fragilis (Sacchoramyces fragilis), and some Aspergillus species are the most prevalent fungal sources of $\beta$-galactosidases that have been approved by the FDA as "generally regarded as safe." Extracellular $\beta$-galactosidase produced by Aspergillus oryzae is utilised commercially (Kazemi et al. 2016). $\beta$-galactosidases are found in abundance in plant tissues. Plant development, fruit ripening and lactose hydrolysis are just a few of the biological processes that these enzymes have been linked to. The significance of $\beta$-galactosidases in fruit development and ripening was also investigated using molecular methods (Li et al. 2001).

In Pichia pastoris, recombinant $\beta$-galactosidase was expressed in a specified medium including metal, where both magnesium and zinc were required to promote cell growth, but at substantially lower levels than in the control. When the medium was reconstituted with only zinc and magnesium, the cells proliferated to 12-15 generations. The quantities of trace metals significantly improved the product yields of recombinant $\beta$-galactosidase (Husain, 2010).

Two types of $\beta$-galactosidases are of increasing significance in industrial processing. They are thermostable and cold-active $\beta$-galactosidases. The thermostable $\beta$-galactosidase from Aspergillus niger, Bacillus stearothermophilus, Pyrococcus woesei, Thermus sp. are relatively stable from 35 to $80^{\circ} \mathrm{C}$. Cold-active and cold-adapted $\beta$-galactosidase from psychrophilic microorganisms are relatively stable from 0 to $25^{\circ} \mathrm{C}$ (Rosenberg, 2006; Husain, 2010).

\section{Mechanism of hydrolysis}

The disaccharide $\beta$-D-galactopyranosyl-(1/4)-Dglucose (lactose) is hydrolysed by $\beta$-galactosidases into $\beta$-D-galactose and $\mathrm{D}$-glucose. The mechanism of action of $E$. coli $\beta$-galactosidase has been widely researched. Because the active site fold is conserved, the general mechanism of commercial lactases is likely to be comparable. A holding glycosidase is $\beta$-galactosidase. It uses a double-displacement reaction to hydrolyse its substrates, resulting in a product with the same stereochemistry as the starting state. One glutamic acid in the active centre gives a proton to lactose's glycosidic oxygen, breaking the molecule and releasing glucose into the medium with the help of magnesium. As a result, the galactose is covalently bonded to the enzyme. In the hydrolytic reaction, the galactosylenzyme intermediate combines with water, releasing galactose and preparing the enzyme for the next round. The active site residues in the K. lactis enzyme are assumed to be Glu551 and Glu482, and in the $A$. oryzae lactase, Glu200 and Glu298 based on homology to similar enzymes, and the crystal structures. A transglycosidation process happens when the galactosyl-enzyme intermediate combines with another sugar (e.g., lactose, glucose, or galactose) instead of water to produce oligosaccharides. At high lactose concentrations, this reaction can become quantitatively significant. Lactases from different microorganisms have a considerable variance in transglycosidation reaction efficiency, resulting in the utilisation of distinct enzymes for lactose hydrolysis and GOS production applications (Dekker, 2011).

\section{Methods of Immobilization of $\beta$-galactosidase}

The immobilization of enzymes is a widely used approach for obtaining reusable enzyme derivatives 
which reduces the high enzyme cost associated with their production and purification (Husain, 2010). Immobilization methods can be physical adsorption, entrapment method, covalent binding method, chemical aggregation, microencapsulation and bioaffinity immobilization. Among all the methods physical adsorption is the simplest method.

\section{Applications of $\beta$-galactosidase in Dairy and Food Industry}

For the production of lactose hydrolysed UHT milk, $\beta$-galactosidase enzyme is used in a process in which lactase was sterile filtered into the package after the UHT treatment. Lactose crystallization in frozen and condensed milk products can be prevented by hydrolysis of lactose in milk for food processing. Enzymatic hydrolysis of lactose in yogurt mixes would reduce the lactose content and make the yogurt more digestible by lactose-sensitive, lactase-deficient individuals. Lactose hydrolysis by $\beta$-galactosidase found in whey can be used to make sweet syrup (used as a source of sugar in confectionary, feedstuffs, soft drinks, sweets, baking, ice-cream, dairy desserts, molasses). Other products like flavoured milk, dairy powders, heat desiccated products such as khoa were also prepared by lactose hydrolysed milk.

Microbial $\beta$-galactosidase production is an important area in whey utilization and treatment or bioconversion of whey into commercially important products are gaining importance. In biotechnological processes, an ultrasonication method is widely used for laboratory scale work. Sonication resulted in release of higher $\beta$-galactosidase activity from lactic acid bacterial cells. Galactooligosaccharides (GOS) are produced simultaneously during lactose hydrolysis due to transgalactosylation activity of $\beta$-galactosidase. GOS are currently used as low-calorie sweeteners, food ingredients, and cosmetic additives. Acid lactase are used as dietary supplements.

\section{Regulations}

Lactase ( $\beta$-galactosidase) is permitted as a nutraceutical ingredient at the level3,000-9,000 IU (or FCC units) / day (FSSAI, 2015). Residual amount of lactase enzyme from Kluyveromyces lactis and Bacillus circulans for treatment or processing of raw materials, foods or ingredients $((\mathrm{mg} / \mathrm{Kg})$ not more than $)$ is given as GMP (FSSAI, 2020). Food enzymes ( $\beta$-galactosidase from Bacillus circulans M3-1) is intended to be used in the production of GOS at a recommended use level of up to $2 \mathrm{~g}$ food enzyme preparation/ $\mathrm{kg}$ lactose (EFSA, 2019).

Low lactose milk shall have less than $1 \%$ lactose and lactose free milk shall have less than $0.1 \%$ lactose (FSSAI, 2020).

\section{Lactose Hydrolysed Milk}

Lactose free milk produced using immobilized lactase enzyme showed maximum activity at a concentration of $39.33 \mathrm{IU} / \mathrm{mg}$ at $50^{\circ} \mathrm{C}$ and $\mathrm{pH} 9$ and the lactase enzyme $(64.53 \mathrm{IU} / \mathrm{ml})$ was isolated from Enterobacter cloacae and immobilised via entrapment using alginate gel (2\%) gives $46.67 \%$ hydrolysis (Bashir et al. 2020).

$\beta$-galactosidase was used for production of lactosehydrolysed UHT milk in a process where lactase was sterile filtered into the package after UHT treatment with limited degree of hydrolysis between 80 and $90 \%$ to avoid excessive sweetness (Harju et al. 2012). Lactose-hydrolysed milk can be used for the preparation of flavoured milk, cheese and yoghurt. Immobilized $\beta$-D-galactosidase from $K$. fragilis can be used for the production of frozen dairy products, to avoid lactose crystallization and to enhance the digestibility and flavour. Lactozym ${ }^{\mathrm{TM}}$ immobilized on cellulose beads resulted in $60 \%$ hydrolysis of milk lactose within $5 \mathrm{~h}$. High degrees of conversion (85-90\%) of lactose in saline solution, whey, whey permeates and skimmed milk obtained from immobilized $\beta$-D-galactosidase from $K$. lactis (Panesar et al. 2010).

\section{Yoghurt}

Compared to normal yoghurt lactose hydrolysed yoghurt have higher rate of lactic acid production, reduced whey separation and improved flavour, body and texture. Enzymatic hydrolysis of lactose 
in yogurt mixes make the yogurt more digestible by lactose-sensitive, lactase-deficient individuals. Lactose hydrolysed yoghurt have several advantages over normal yoghurt. Lactose hydrolysed yoghurt have increased sweetness and flavour acceptance and faster acid development or a shorter coagulation time compared to normal yoghurt (Dekker, 2019).

\section{Frozen Dairy Products}

In frozen dairy products there will be decrease in the freezing point due to lactose hydrolysis. Thus, it can improve smoothness and scoopability of the product (Dekker, 2019). $\beta$-galactosidase prevented the crystallization of lactose by breaking into glucose and galactose and reduced sandiness. Replacement of $75 \%$ of MSNF with lactose hydrolysed demineralized whey powder, gave acceptable product with improved creaminess (Panesar et al. 2010). Replacing $25 \%$ of MSNF by lactose hydrolysed whey in ice cream, ice milk, milk shake and low-calorie frozen dessert mixes improved organoleptic and physical quality of such product (Martinez and Speckman, 1988).

\section{Food Syrups and Sweeteners}

Hydrolysis of whey using $\beta$-D-galactosidase have an important application of enzyme technology in food industry. In soft drinks and canned fruit syrup, concentrated hydrolysed whey or whey permeates can be used as a sweetener. Sweet syrup obtained by the hydrolysis of whey can be used in confectionary, feedstuffs, sweets, baking, ice-cream, dairy dessert, molasses (Panesar et al. 2010; Nivetha and Mohanasrinivasan, 2017).

\section{Cheese}

Cheese whey consists $0.7 \%(\mathrm{w} / \mathrm{v})$ protein, $5 \%(\mathrm{w} / \mathrm{v})$ lactose, $93 \%(\mathrm{w} / \mathrm{v})$ water and $0.5 \%(\mathrm{w} / \mathrm{v})$ minerals. Whey is a highly polluting substance in the cheese industry. It is cheap and a readily available substrate for microbial cell cultivation after the hydrolysis of lactose using $\beta$-galactosidase (Rech and Ayub, 2007). $\beta$-galactosidase used to improve the production and ageing of cheddar cheese, there will be an increase in the ratio of soluble nitrogen/total nitrogen and non-protein nitrogen. Cheese production is faster and cheaper with improved organoleptic properties in this method. Compared to normal milk cheese, cheese manufactured from hydrolysed milk ripens more quickly. Since whey is an easily available abundant by-product in the cheese industry, galactooligosaccharides (GOS) can be readily manufactured by enzymatic transgalactosylation of $\beta$-galactosidase from whey lactose (Panesar et al. 2010).

Cheese maturation or cheese ripening is a process carried out for developing unique flavour, aroma and texture in cheese. Ripening of cheese is done for usually 6 months to 2 years depending upon the variety of cheese (Anjani et al.2007). There are different methods such as elevation of ripening temperature, use of modified starters or addition of adjunct cultures can be used to enhance cheese ripening and exogenous enzyme addition. The addition of exogenous enzymes is considered to be the simplest and most specific than others. Because of the loss of enzyme in the whey, poor enzyme distribution, reduced yield, and poor quality cheese, adding free enzymes to milk during cheese preparation has been proven to be unfavourable (Kailasapathy and Lam, 2005). These drawbacks can be eliminated by making use of encapsulated enzymes. The enzyme will be physically separated from its substrate in the milk and curd mixture during cheese making by microcapsule. The enzyme in whey is only released into the cheese matrix upon capsule breakdown during ripening (Bashir et al. 2020).

\section{Other Products}

Flavoured lactose-free milk has much less problems with Maillard-related off-flavours and browning than regular lactose-free UHT milk because it has strong flavour and colour. Dairy powders can be produced from milk or whey that is made lactose-free by lactase. Lactose hydrolysis into glucose and galactose affect the drying of milk products by promoting greater adhesion to equipment, greater tendency to browning and decreased solubility and modification 
of microstructure (Torres et al. 2017; Dekker et al. 2019). Lactose in the concentrated paneer whey was hydrolysed up to $55 \%$ using $\beta$-galactosidase in the preparation of different formulations of buttermilk. Buttermilk prepared by blending with dahi (1:1) was highly acceptable and also replace milk solids with whey solids by $50 \%$ (Singh et al. 2019). Aggarwal et al. (2019) suggested addition of $1.5 \mathrm{ml}$ enzyme/2.5 L milk gave khoa optimum physico-chemical and textural characteristics. Hydrolysis of lactose increases the sweetness of the product, which lowered the level of added sugar in the product. Hydrolysis of $70 \%$ of lactose in milk increases sweetness by an amount corresponding to an addition of about $2 \%$ sucrose. In heat-treated products, an increase of reducing sugars causes more intensive Maillard reactions (Harju et al. 2012).

\section{Role of $\beta$-galactosidase in Whey Utilization}

Disposal of whey which contain high BOD (5-6\% dissolved solids) is a major problem in dairy industry. Bioconversion of whey by $\beta$-galactosidase is an important area in the utilization of whey. Ethanol production using $\beta$-galactosidase synthesized by Kluyveromyces sp. where whey permeates and cheese whey powder as growth medium to solve the byproducts problems from cheese manufacturing industries (Asraf and Gunasekaran, 2010; Nath et al. 2014). Whey lactose enzymatic hydrolysis makes the bioremediation processes and biomolecules and biomass productions viable with the use of these kinds of whey as cultivation media (Dutra Rosolen et al. 2015).

Production and purification of $\beta$-galactosidase enzyme from safe Lactobacillus cultures is an alternative source of biological enzyme for the preparation of lactose hydrolysed milk for lactose intolerant population. Sonication treatment optimized for $5 \mathrm{~min}$ (pulse $15 \mathrm{sec}$ off / $30 \mathrm{sec}$ on at $55 \%$ amplitudes) was found to be best for production of $\beta$-galactosidase (Makwana et al. 2017).

\section{Lactose Hydrolysed Whey Products}

Utilization of $20 \%$ lactose hydrolysed paneer whey (60\% hydrolysis) in the bun gave desirable colour and flavour. Concentrated (20\%) and lactose hydrolysed $(60 \%)$ paneer whey and wheat flour ( $25 \%$ replacement of maida) could be successfully utilized for the production of buns (Reddy et al. 2016). Whey was utilized for developing carbonated lemon beverage. Lactose hydrolysed carbonated lemon paneer whey beverage with acceptable quality can be prepared using lemon juice and the whey beverage was acceptable up to 49 days at refrigerated temperature (Rajendrabhai and Prajapati, 2017). Fruit candy were prepared using hydrolysed paneer whey along with beetroot powder and pomegranate powder at rate of hydrolysis of $90 \%$. They reported that hydrolysis reduces the sucrose quantity to be added and prevented crystallization during storage as compared to the control (Bansi, 2020). For the preparation of candy, $84.35 \%$ lactose hydrolysed cheddar cheese whey was used and they have reported that the candy has acceptable quality using sugar $(22 \%)$ and stabilizer (CMC $0.4 \%)$. The sugar addition in lactose hydrolysed whey was less compared to unhydrolyzed whey (34\%) (Raval, 2014).

\section{$\beta$-galactosidase for Bread Making}

Skim milk solids are used in bread, contributing about $1.5 \%$ lactose. Lactose so incorporated is not yeastfermentable and imparts no additional sweetness on an overall basis. Hydrolysis by $\beta$-galactosidase impart sweetness. The hydrolysis products glucose and galactose can be useful for fermentation and crust colour formation respectively (Shukla and Wierzbicki, 1975).

\section{Galacto-oligosaccharides (GOS)}

GOS are nondigestible prebiotics, aid to modify intestinal microflora for human health. In human milk GOS influences growth of Bifidobacteria in the gastrointestinal tract of newly born and breast-fed infants. It also promotes the growth of useful bacteria in the intestine. GOS can be produced simultaneously during lactose hydrolysis due to transgalactosylation activity of $\beta$-galactosidase (Nath et al. 2014; Saqib et al. 2017). GOS can be applied in the production of 
low-calorie sweeteners, cosmetic additives and foods such as soft drinks, cookies, cereals, chewing gums, candies, ice cream, yoghurt and powdered milk (Rosenberg, 2006).

\section{Biotechnological Applications of $\beta$-galactosidases}

Enzyme hydrolysis of lactose is a common biotechnological approach as the hydrolysed products can be consumed by lactose maldigesters. To improve the flavour of lactose-hydrolyzed milk, $\beta$-galactosidase is immobilized in liposomes. Coldactive $\beta$-galactosidase hydrolyses lactose and it is an important food-industrial enzyme. Thermophilic $\beta$-galactosidases are useful alternative to the mesophilic enzymes used in the industrial processing of dairy products along with heat treatment to sterilize the product. Whole cells as a source of $\beta$-galactosidaseused for thelactosehydrolysis through permeabilization technology. Saccharification of milk whey using ethanol permeabilized cells in packed bed bioreactors indicated that permeabilization increases the lactose hydrolysis rate and $99.5 \%$ of milk whey lactose was hydrolysed at $30^{\circ} \mathrm{C}$ for $30 \mathrm{~h}$. Sonication resulted in release of higher $\beta$-galactosidase activity from lactic acid bacterial cells. Whey proteins are ultrafiltered and hydrolyzed to produce a variety of valuable pharmaceutical products (Pessela et al. 2003; Husain, 2010; Nivetha and Mohanasrinivasan, 2017).

\section{Dietary Supplements}

Acid lactase are used as dietary supplements and most commonly used acid lactase is obtained from A. oryzae. Enzyme properties for considering as dietary supplements includes, should be stable and preferably active at the low stomach $\mathrm{pH}$, resistant to drying since it is formulated in pills, should not be vulnerable to proteolytic degradation to extend its life span in the stomach. Enzyme preparation should have a high strength so that pills can be relatively small. Enzyme should be ingested immediately before or during the meal and will be active in the stomach (Stocker et al. 2016).

\section{Industrial Sources}

Neutral lactases are sold by companies like DSM Food-Specialties (Maxilact $\AA$ neutral lactase enzymes), DuPont (GODO-YNL2), Chr. Hansen (HA-LACTASE $\left.{ }^{\mathrm{TM}}\right)$, Kerry (Biolactase $^{\mathrm{TM}}$ lactase enzyme), Novozymes (Lactozyme $\left.{ }^{\circledR}\right)$ Amano Enzyme Inc. (Lactase 14-DS.) and Shin Nihon, and DSM Nutritional Ingredients (Tolerase ${ }^{\mathrm{TM}} \mathrm{L}$, an acid lactase).

\section{CONCLUSION}

$\beta$-galactosidase is a key enzyme in the food processing industry, with nutritional, technological, and environmental uses. Because of their beneficial effect on the gut bacterial microflora, they are widely used in a range of foods. Enzyme immobilization allows for enzyme reutilization and, in some cases, improved activity by supplying the enzyme with a more favourable micro-environment.

\section{REFERENCES}

Aggarwal, A., Seth, R., Gandhi, K. and Wangdare, S. 2019. Physico-chemical properties of Khoa prepared from lactose hydrolyzed buffalo milk. Journal of Food Science and Technology, 56(6): 3067-3076.

Anjani, K., Kailasapathy, K. and Phillips, M. 2007. Microencapsulation of enzymes for potential application in acceleration of cheese ripening. International Dairy Journal, 17(1): 79-86.

Ansari, S.A., Satar, R., Kashif Zaidi, S. and Ahmad, A. 2014. Immobilization of Aspergillus oryzae $\beta$-galactosidase on cellulose acetate-polymethylmethacrylate membrane and its application in hydrolysis of lactose from milk and whey. International Scholarly Research Notices, 2014.

Asraf, S.S. and Gunasekaran, P. 2010. Current trends of $\beta$-galactosidase research and application. Current research, technology and education topics in applied microbiology and microbial biotechnology. Microbiology Book Series Formatex Research Center, Spain, pp. 880-890.

Bashir, N., Sood, M. and Bandral, J.D. 2020. Enzyme immobilization and its applications in food processing: A review. International Journal of Chemical Studies, 8(2): 254261.

Dekker, P.J.T. 2011. Enzymes exogenous to milk in dairy technology: $\beta$-D-Galactosidase. In: John W. Fuquay (Ed.), Encyclopedia of Dairy Sciences ( ${ }^{\text {nd }}$ ed., pp. 276-283). London: Elsevier Academic Press. 
Dekker, P.J., Koenders, D. and Bruins, M.J. 2019. Lactosefree dairy products: market developments, production, nutrition and health benefits. Nutrients, 11(3): 551.

Downs, M.L., Kabourek, J.L., Baumert, J.L. and Taylor, S.L. 2013. Milk protein allergy. Milk and dairy products in human nutrition: production, composition and health, pp. 111-128.

Dutra Rosolen, M., Gennari, A., Volpato, G. and Volken de Souza, C.F. 2015. Lactose hydrolysis in milk and dairy whey using microbial $\beta$-galactosidases. Enzyme Research, 1-7.

EFSA Panel on Food Contact Materials, Enzymes and Processing Aids (CEP), 2019. Safety evaluation of the food enzyme beta-galactosidase from Bacillus sp. (strain M3-1). EFSA Journal, 17(10): 1-10.

El-Gindy, A. 2003. Production, partial purification and some properties of $\beta$-galactosidase from Aspergillus carbonarius. Folia Microbiologica, 48(5): 581.

FSSAI, 2020. Food Safety and Standards (Food Products Standards and Food Additives) Regulations, Food Safety and Standard Authority of India, New Delhi.

FSSAI, 2015. Food Safety and Standards (Food Product Standards and Food Additives) Regulations on Nutraceuticals, Food Safety and Standards Authority of India, New Delhi.

Genari, A.N., Passos, F.V. and Passos, F.M.L. 2003. Configuration of a bioreactor for milk lactose hydrolysis. Journal of Dairy Science, 86(9): 2783-2789.

Ghatak, A., Guha, A.K. and Ray, L. 2013. Immobilization of $\beta$-galactosidase from Enterobacter cloacae: Characterization and its use in the continuous production of low lactose milk.

Harju, M., Kallioinen, H. and Tossavainen, O. 2012. Lactose hydrolysis and other conversions in dairy products: Technological aspects. International Dairy Journal, 22(2): 104-109.

Husain, Q. 2010. $\beta$-Galactosidases and their potential applications: a review. Critical Reviews in Biotechnology, 30(1): 41-62.

Ibrahim, S.A. and Gyawali, R. 2013. Lactose intolerance. Milk and dairy products in human nutrition: Production, composition and health, pp. 246-260.

Kailasapathy, K. and Lam, S.H. 2005. Application of encapsulated enzymes to accelerate cheese ripening. International Dairy Journal, 15(6-9): 929-939.

Kazemi, S., Khayati, G. and Faezi-Ghasemi, M. 2016. $\beta$-galactosidase production by Aspergillus niger ATCC 9142 using inexpensive substrates in solid-state fermentation: Optimization by orthogonal arrays design. Iranian Biomedical Journal, 20(5): 287.
Li, S.C., Han, J.W., Chen, K.C. and Chen, C.S. 2001. Purification and characterization of isoforms of $\beta$-galactosidases in mung bean seedlings. Phytochemistry, 57(3): 349-359.

Mahoney, R.R. 2002. Beta-Galactosidase. In Handbook of food enzymology (pp. 838-843). CRC Press.

Makwana, S., Hati, S., Parmar, H. and Aparnathi, K.D. 2017. Process optimization for the production of $\beta$-galactosidase using potential Lactobacillus cultures. International Journal of Current Microbiology and Applied Sciences, 6(8): 1454-1469.

Martinez, S.B. and Speckman, R.A. 1988. $\beta$-galactosidase treatment of frozen dairy product mixes containing whey. Journal of Dairy Science, 71(4): 893-900.

Nath, A., Mondal, S., Chakraborty, S., Bhattacharjee, C. and Chowdhury, R. 2014. Production, purification, characterization, immobilization, and application of $\beta$ galactosidase: a review. Asia-Pacific Journal of Chemical Engineering, 9(3): 330-348.

Nivetha, A. and Mohanasrinivasan, V. 2017. Mini review on role of $\beta$-galactosidase in lactose intolerance. In IOP Conference Series: Materials Science and Engineering, 263(2): 81-87.

Panesar, P.S., Kumari, S. and Panesar, R. 2010. Potential applications of immobilized $\beta$-galactosidase in food processing industries. Enzyme Research, pp. 1-16.

Pessela, B.C.C., Mateo, C., Fuentes, M., Vian, A., García, J.L., Carrascosa, A.V. and Fernandez-Lafuente, R. 2003. The immobilization of a thermophilic $\beta$-galactosidase on Sepabeads supports decreases product inhibition: Complete hydrolysis of lactose in dairy products. Enzyme and Microbial Technology, 33(2-3): 199-205.

Rajendrabhai, P.R. and Prajapati, J.P. Technology for Carbonated Lemon whey Beverage. International Journal of Innovative Science and Research Technology, 2(7): 448-458.

Raval, H.B. 2014. Preparation of Candy from Lactose Hydrolyzed Whey (M. Tech. Thesis, Anand Agricultural University, Anand).

Rech, R. and Ayub, M.A.Z. 2007. Simplified feeding strategies for fed-batch cultivation of Kluyveromyces marxianus in cheese whey. Process Biochemistry, 42(5): 873-877.

Reddy, P.V.S., Nath, B.S. and Reddy, K.P. 2016. Utilization of concentrated and lactose hydrolyzed whey in the preparation of buns. World Journal of Pharmaceutical Research, 5(4): 1581-1609.

Rosenberg, Z.M.M. 2006. Current trends of $\beta$-galactosidase application in food technology. Journal of Food and Nutrition Research, 45(2): 47-54.

Saqib, S., Akram, A., Halim, S.A. and Tassaduq, R. 2017. Sources of $\beta$-galactosidase and its applications in food industry. 3 Biotech, 7(1): 79. 
Shukla, T.P. and Wierzbicki, L.E. 1975. Beta-galactosidase technology: A solution to the lactose problem. Critical Reviews in Food Science \& Nutrition, 5(3): 325-356.

Singh, T.P., Nath, B.S., Veena, N., Amaladhas, P.H. and Emerald, F.M.E. 2019. Utilization of lactose hydrolysed paneer whey for the preparation of Buttermilk. Indian Journal of Dairy Science, 72(4): 358-364.
Stocker, B., Grundmann, S., Mosters, P., Nitzsche, P. and Brehler, R. 2016. Occupational sensitization to lactase in the dietary supplement industry. Archives of Environmental EOccupational Health, 71(5): 259-267.

Torres, J.K.F., Stephani, R., Tavares, G.M., de Carvalho, A.F., Costa, R.G.B., de Almeida, C.E.R. and Perrone, Í.T. 2017. Technological aspects of lactose-hydrolyzed milk powder. Food Research International, 101: 45-53. 